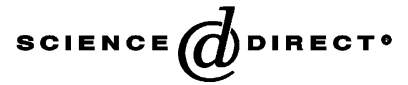

International Journal of Pharmaceutics 285 (2004) 13-21 $\overline{\text { international }}$

journal of

pharmaceutics

www.elsevier.com/locate/ijpharm

\title{
Polymorphism of pindolol, 1-(1H-indol-4-yloxyl)-3-isopropylamino-propan-2-ol
}

\author{
Sandra C.C. Nunes, M. Ermelinda Eusébio*, M. Luísa P. Leitão, J.S. Redinha \\ Departamento de Química, Faculdade de Ciências e Tecnologia, Universidade de Coimbra, 3004-535 Coimbra, Portugal
}

Received 13 January 2004; received in revised form 21 June 2004; accepted 6 July 2004

Available online 11 September 2004

\begin{abstract}
Crystallization of pindolol from the melt was studied by differential scanning calorimetry (DSC) and polarized light thermomicroscopy (PLTM) in order to discriminate the polymorphic forms obtained by this method. The crystallization process originates one exothermic signal localized in two different well-defined temperature ranges. Fusion gives rise to overlapped curves, which were analysed by peak-fitting. The polymorphs were identified as the clusters formed with the values obtained for $T_{\text {peak }}$ of the component curves. Three polymorphic forms were exhibited by pindolol crystallized from the melt. Commercial pindolol presents only two of these forms.
\end{abstract}

(C) 2004 Elsevier B.V. All rights reserved.

Keywords: Pindolol; Recrystallization from melt; Polymorphism

\section{Introduction}

This paper deals with the study of polymorphism of pindolol (Fig. 1), a beta-adrenoreceptor antagonist with partial agonist activity. The importance of polymorphism in pharmaceuticals makes its study a relevant matter, either on the theoretical or on the practical point of view.

Like most organic compounds, pindolol can present different structural arrangements in the solid state. The diversity of structures exhibited by this type of com-

\footnotetext{
* Corresponding author. Tel.: +351 239852 080; fax: +351239827 703 .

E-mail address: quierme@ci.uc.pt (M.E. Eusébio).
}

pounds can result from different hydrogen bond networks and from different conformations of the nonpolar molecular segments between the polar centres involved in intermolecular interactions. Those polymorphs differing among themselves in conformation of the non-polar parts have close energy values because only dispersion forces are involved (Bernstein, 1987; Brittain and Byrn, 1999).

Another problem to be faced on running research programs on polymorphism of organic compounds is the simultaneous presence of several crystalline forms generated in crystallization processes from solvents or from melts (Bernstein et al., 1999). Solidification, as an activated process occurring in supersaturated solutions or in supercooled melts, gives rise to metastable 


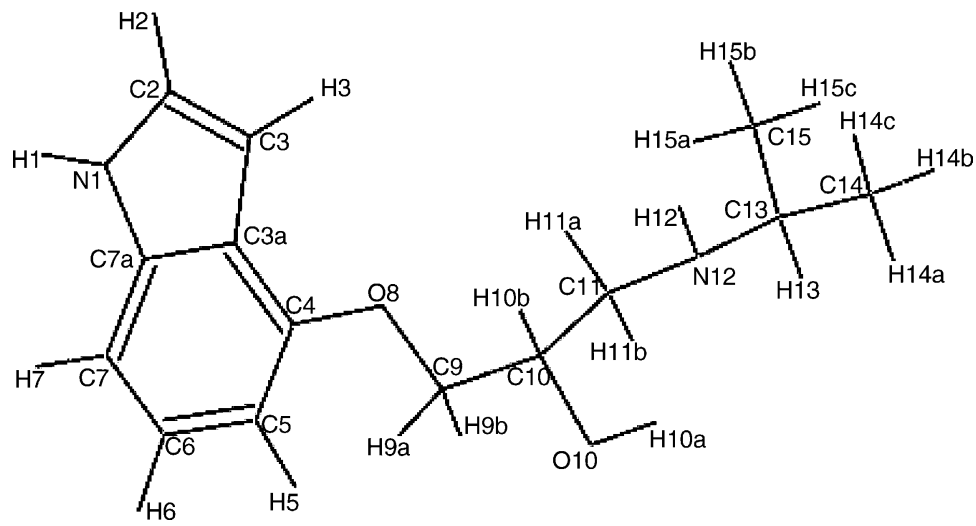

Fig. 1. Molecular structure of pindolol.

forms accompanying the thermodynamic stable one (Mullin, 1993). Furthermore, organic solids often grow as imperfect crystalline lattices, giving rise to semicrystalline or even amorphous material. Attention has to be paid to this point to avoid misunderstanding polymorphic forms with poorly ordered material.

On studying polymorphism of organic compounds, one expects to find complex mixtures of close energy crystalline forms, often containing solid material with different crystallinity degree. Thence, to get reliable data, accurate experiments and sensitive methods are required.

The pindolol specimens used for searching polymorphs were the original material supplied by a commercial firm, and the solid samples prepared by cooling molten pindolol. The discrimination of the two sources is obvious as the generated polymorphs depend on the conditions under which they are formed.

This research program on polymorphism was carried out by differential scanning calorimetry (DSC) and polarized light thermomicroscopy (PLTM). Data collected from successive cooling/heating cycles recorded between 25 and $175^{\circ} \mathrm{C}$ are used to identify the solid structures of pindolol.

\section{Materials and methods}

The original substance used for the preparation of the samples studied in this work was supplied by Sigma-Aldrich. Tested by HPLC, the purity found was higher than $99 \%$. The chromatograms were obtained with Merck Hitachi L3000 equipment under the following experimental conditions: column, spherisorb ODS2RP18; mobile phase, mixture of $0.025 \mathrm{M}$ potassium phosphate aqueous solution $(\mathrm{pH}=4.5)$, and acetonitrile, $92: 8(\mathrm{v} / \mathrm{v})$ with $1.5 \mathrm{ml} / \mathrm{min}$ flow; detection, UV photodiode $(\lambda=230 \mathrm{~nm})$.

DSC Pyris 1 calorimeter equipped with Cryofill cooling system and DSC7 calorimeter equipped with CCA7 cooling unit, both from Perkin Elmer, were used. Mass of the substance in the range of $1.5-3 \mathrm{mg}$ was encapsulated in aluminium pans recommended for volatile samples. The calorimetric reference was the empty pan. For reasons explained later on, special attention was paid to the sample assembling in order to avoid the presence of oxygen. The pan containing the substance was left in a dry nitrogen box for enough time to purge air off the sample, and then sealed inside the box.

The calorimeter was calibrated for temperature with $99.9 \%$ pure cyclohexane $\left(T_{\text {fus }}=6.66 \pm 0.04{ }^{\circ} \mathrm{C}\right)$ (Sabbah et al., 1995) and $99.99 \%$ indium $\left(T_{\text {fus }}=\right.$ $156.60^{\circ} \mathrm{C}$ ) (Sabbah et al., 1995). Enthalpy calibration was performed with indium $\Delta_{\text {fus }} H=3286 \pm 13 \mathrm{~J} \mathrm{~mol}^{-1}$ (Sabbah et al., 1995). A $20 \mathrm{ml} / \mathrm{min}$ nitrogen purging flow was used.

As a rule, four heating/cooling cycles were performed between 25 and $175^{\circ} \mathrm{C}$ for each sample. At temperatures below $25^{\circ} \mathrm{C}$, no phase transitions were observed.

The samples for thermomicroscopic studies were prepared by dispersing as isolated particles a small amount of the solid at the bottom of a covered 7-mm 
quartz crucible. This procedure allows the observation in the same test of the behaviour of several particles during successive heating and cooling runs.

The samples were studied in heating/cooling cycles between $25^{\circ} \mathrm{C}$ and the melting point, at scanning rates between 1 and $10^{\circ} \mathrm{C} / \mathrm{min}$. The scans were made under a nitrogen atmosphere through the use of a nitrogen flow.

The hot stage/DSC video microscopy analysis was performed using a Linkam system DSC 600. For the optical observation, we used a Leica DMRB microscope, a Sony CCD-IRIS/RGB video camera. For image analysis, a Linkam system software with Real Time Video Measurement System was used. The images were obtained by combined use of polarized light and wave compensators, using a $200 \times$ magnification.

\section{Results and discussion}

\subsection{Preliminary DSC studies}

Preliminary tests, performed with samples sealed in open atmosphere and submitted to successive heating/cooling runs, pointed out differences between the first and the subsequent fusion curves. In fact, the first fusion curve is narrower and exhibits a maximum at higher temperature than the others. A typical experiment is illustrated by Fig. 2, which corresponds to a sample submitted to four heating/cooling runs. The peak temperature $T_{\text {peak }}$ decreases about $3{ }^{\circ} \mathrm{C}$ from the first to the second fusion and then remains constant. The curves after the first fusion are tailed giving an onset temperature $T_{\text {on }}, 3-4{ }^{\circ} \mathrm{C}$ below that given by the first curve. A decrease in fusion enthalpy $\Delta_{\text {fus }} H$, of about $5 \mathrm{~kJ} \mathrm{~mol}^{-1}$ between the first fusion and the subsequent ones, is also observed.

The difference between the results found for the first fusion and the subsequent ones can be understood by admitting the oxidation of molten pindolol by oxygen. Although the instrument is purged by a nitrogen flow, the air imprisoned inside the pan is not removed and some pindolol is oxidised as fusion occurs. The oxidation comes to the end as oxygen is used up by the reaction with pindolol, what happens in particular in the first fusion process. The oxidation product acts as impurity, giving rise to tailed fusion curves, with the temperature maximum shifted towards lower temperature and to a decrease of the fusion enthalpy.

The interpretation presented herein is quite understandable as indole is readily oxidised by a variety of reagents including oxygen. In fact, indole is chemically oxidised, giving rise to indoxyl (3-hydroxyindole) and thence to indigo (Remers, 1972). Stenlake (1979) reports the light catalysed oxidation of indole on exposure to air yielding the compounds described above. An analytical method for quantitative determination of pindolol based on the oxidation of indole moiety by some reagents was developed in a previous work (Mahrous et al., 1992).

Out of the influence of light, the oxidation of the solid is noticeable only at temperatures close to the

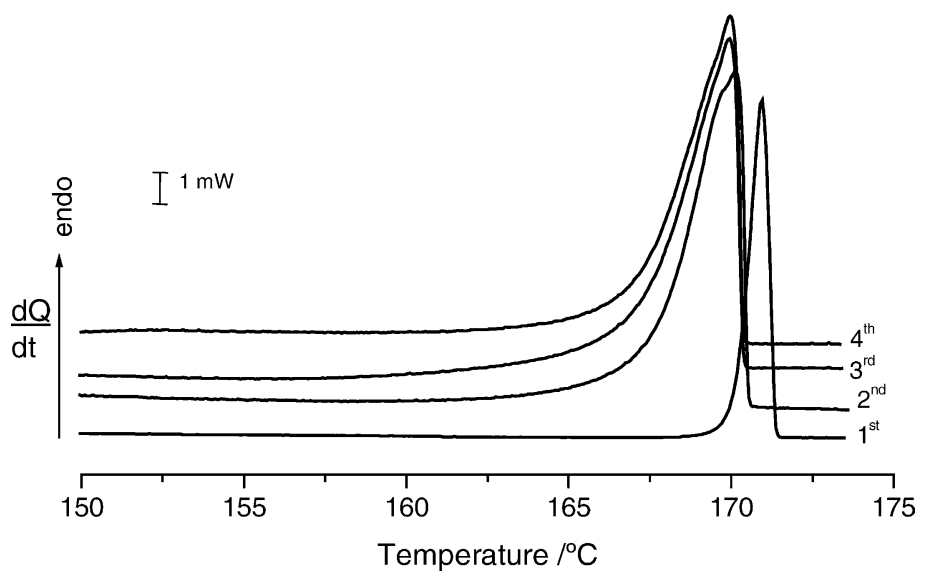

Fig. 2. Sequential DSC heating runs carried on pindolol assembled in air atmosphere $\left(m=2.12 \mathrm{mg}\right.$, heating rate $\left.=1^{\circ} \mathrm{C} / \mathrm{min}\right)$. 


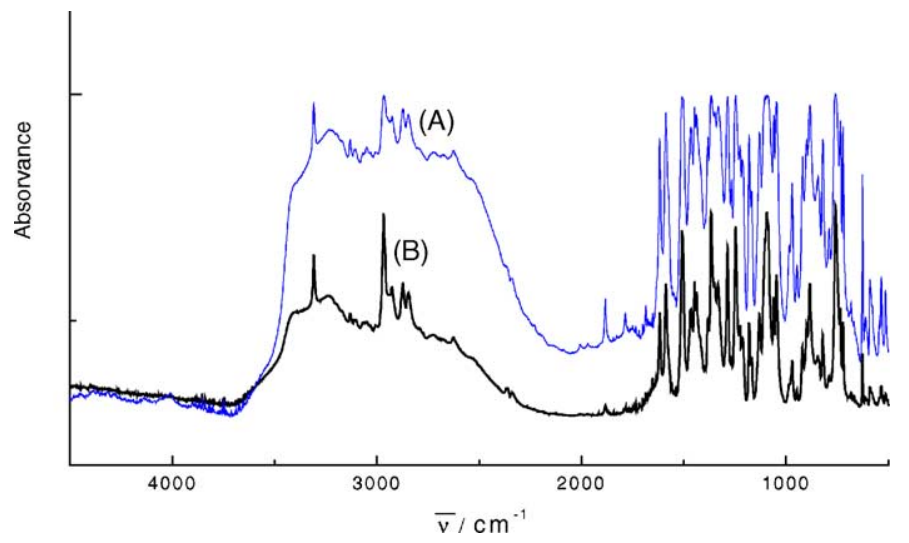

Fig. 3. Infrared spectra of the original pindolol (A) and of a sample melted in air atmosphere (B).

melting point. In fact, the first fusion curves for samples assembled in contact with air do not differ much from the real ones. On the contrary, the weakness of the intermolecular hydrogen bonds in the liquid state favours the oxidation of pindolol. The infrared spectrum of the original pindolol and of a sample melted in air atmosphere (Fig. 3) reveals differences related to the oxidation process. The most evident difference is the increasing in the $3000 \mathrm{~cm}^{-1}$ band correspondent to the stretching of the unsaturated $\mathrm{CH}$ bond.

In practice, the problem due to the oxidation of pindolol on heating is overcome by sealing the aluminium pan under nitrogen atmosphere after removing air with a nitrogen flow. This was the procedure followed along this research.

In Fig. 4 are depicted the DSC heating curves recorded for a sample assembled under these experimental conditions submitted to successive heating/cooling cycles. The undesirable effects caused by the presence of oxygen are really eliminated.

\subsection{Thermal behaviour of pindolol}

The search for polymorphs was undertaken either in the original substance purchased from the supplier and used without any further treatment, or in samples prepared by cooling molten pindolol under different cooling rates. Having in mind that the structure exhibited by a given compound can be dependent on the method used in its preparation, it is advisable to analyse separately the fusion curves for solids obtained from both sources.

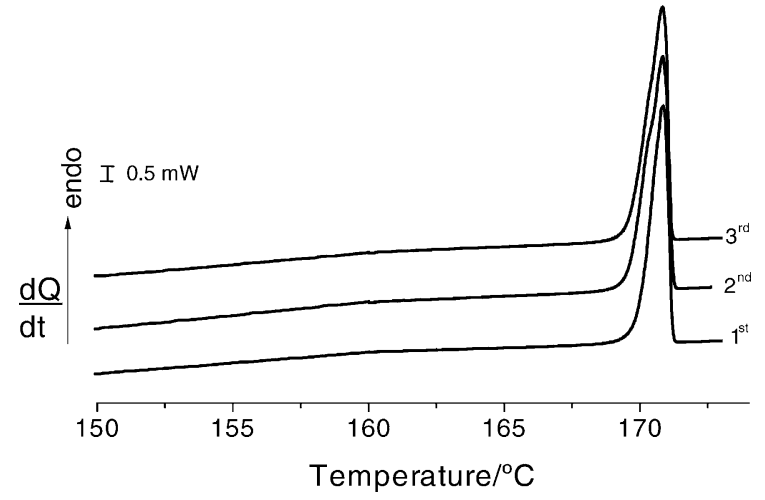

Fig. 4. DSC pattern for successive heating runs carried on a pindolol sample assembled in nitrogen atmosphere. $(m=1.83 \mathrm{mg}$, heating rate $\left.=1^{\circ} \mathrm{C} / \mathrm{min}\right)$.

First of all, let us consider the results obtained for the original samples. The endotherm corresponding to fusion is the unique thermal signal observed for this substance on heating. The fusion curves recorded at any scanning rate between 0.5 and $10^{\circ} \mathrm{C} / \mathrm{min}$ show overlapped curves corresponding likely to different polymorphs.

The analysis of the curves was performed by a peak fit program (Origin, 2002). The best goodness-of-fit was achieved by using the following double asymmetric sigmoidal equation

$y=A \frac{1}{1+e^{\left(x-x_{c}+w_{1} / 2\right) / w_{2}}}\left[1-\frac{1}{1+e^{\left(x-x_{c}-w_{1} / 2\right) / w_{3}}}\right]$

The meaning of the five adjustable parameters is as follows: $A$, area under the curve; $x_{c}$, temperature maxi- 


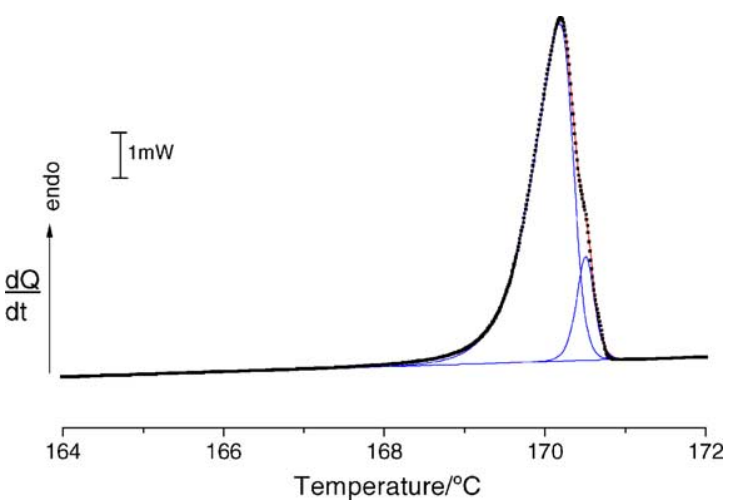

Fig. 5. Component curves obtained in a peak-fitting analysis of a pindolol fusion curve $\left(m=1.53 \mathrm{mg}\right.$, heating rate $\left.=1{ }^{\circ} \mathrm{C} / \mathrm{min}\right)$.

mum; $w_{1}$, peak width; $w_{2}$ and $w_{3}$, parameters accounting for the curve slope at the left and at the right side of the maximum. The experimental DSC signals were fitted with two curves and their characteristic features were determined. An example of the fitting analysis is shown in Fig. 5 for a fusion curve recorded at a scanning rate of $1{ }^{\circ} \mathrm{C} / \mathrm{min}$.

A cluster analysis (Bratchell, 1989) of $T_{\text {peak }}$ values determined for nine samples upon heating at $1{ }^{\circ} \mathrm{C} / \mathrm{min}$ led to the formation of two groups identified as polymorphs: one is characterized by $T_{\text {peak }}=170.2 \pm 0.2^{\circ} \mathrm{C}$ and the other by $T_{\text {peak }}=171.0 \pm 0.3^{\circ} \mathrm{C}$. The value determined for the global enthalpy of fusion was $\Delta_{\text {fus }} H$ $=58.8 \pm 0.8 \mathrm{~kJ} \mathrm{~mol}^{-1}$.

From the area under the component curves, we may conclude that the original pindolol is a mixture of two polymorphs in a ratio estimated to be $3: 1$ of the lowest $T_{\text {peak }}$ relative to that of the highest $T_{\text {peak }}$.

We begin the analysis of the data obtained for the pindolol after the first fusion by considering the crystallization of the melt. It is worth to note that this transformation occurs by rule at two distinct temperature ranges (Fig. 6). For a set of 72 cooling runs corresponding to 18 samples, each of one submitted to four successive heating/cooling cycles recorded at $2{ }^{\circ} \mathrm{C} / \mathrm{min}, 65 \%$ of crystallizations occur at $75 \pm 1{ }^{\circ} \mathrm{C}, \mathrm{LTC}, 28 \%$ at 143 $\pm 7{ }^{\circ} \mathrm{C}$, HTC, and only $7 \%$ at a temperature between these limits. At higher scanning rates, an identical trend is observed although the solidification temperature decreases as the rate increases.

Different values are found for the crystallization enthalpy of the solids obtained at the two temperature

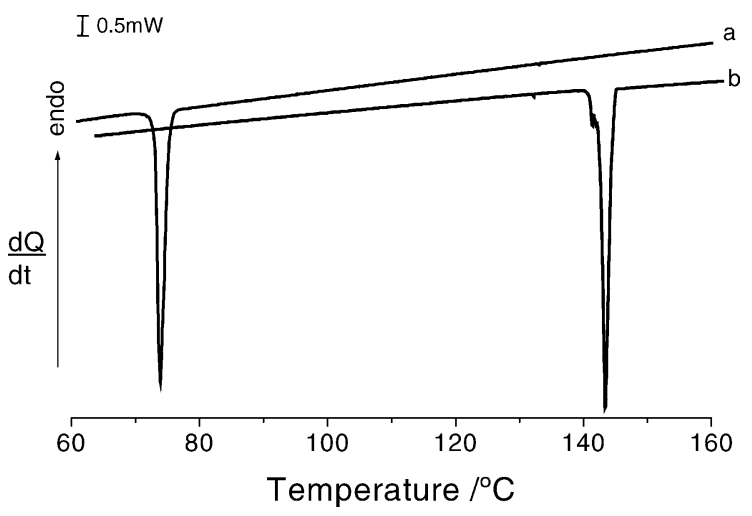

Fig. 6. Crystallization curves obtained in different runs of the same sample. (a) cooling curve for third run; (b) cooling curve for second run $\left(m=2.71 \mathrm{mg}\right.$, cooling rate $\left.=2{ }^{\circ} \mathrm{C} / \mathrm{min}\right)$.

ranges. For the solid obtained at HTC, $\Delta_{\text {crys }} H=-50$ $\pm 3 \mathrm{~kJ} \mathrm{~mol}^{-1}$, whilst for that at LTC, $\Delta_{\text {crys }} H=-30 \pm$ $1 \mathrm{~kJ} \mathrm{~mol}^{-1}$. Both values are below that obtained for the fusion enthalpy, $\Delta_{\text {fus }} H=58 \pm 2 \mathrm{~kJ} \mathrm{~mol}^{-1}$, what means that in particular the solid formed at LTC has low crystallinity. The crystallinity increasing upon heating of the solidification yields can be observed in the DSC curve for the solid obtained at LTC, and is shown in Fig. 7. The structural perfecting is a slow process taking place between 110 and $158^{\circ} \mathrm{C}$.

The crystallization of molten pindolol at two welldefined and distinct temperature ranges can be understood by assuming a phase separation of the melt on cooling before crystallization takes place. The crystallization of one of the liquids requires a supercooling corresponding to HTC, which is within the range

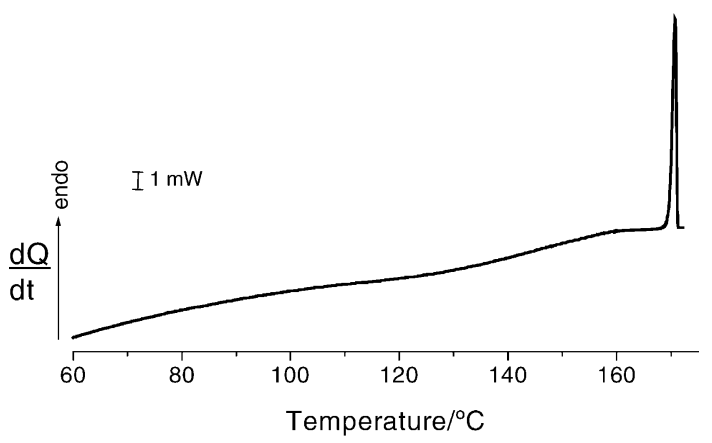

Fig. 7. DSC heating curve for LTC solid obtained by freezing molten pindolol $\left(m=2.97 \mathrm{mg}\right.$, heating rate $=10^{\circ} \mathrm{C} / \mathrm{min}$ from 60 to $160^{\circ} \mathrm{C}$ and $1{ }^{\circ} \mathrm{C} / \mathrm{min}$ from 160 to $175^{\circ} \mathrm{C}$ ). 
expected for most organic substances including melts (Mullin, 1993). The other liquid phase crystallizes at LTC that is at a much higher supercooling.

On cooling the melt, the crystallization is initiated in the liquid phase of lower supercooling. Although the spontaneous nucleation in the other phase would occur at LTC, the presence of the emergent solid phase induces its crystallization due to an effective reduction of surface energy for the solid embryo formation (heterogeneous crystallization) (Oxtoby and Talanquer, 1996). Thence, on thermodynamic grounds, a complete crystallization of molten pindolol should be observed at HTC, that is, around $143^{\circ} \mathrm{C}$.

However, the rate of nucleation in viscous media, as that we are dealing with, is a rather slow process, and even at a low scanning rate, the number of homogeneous nucleated centers would be sometimes negligible (Turnbull and Bagley, 1975). This means that nucleation at HTC can be by-passed. Furthermore, in viscous media, the nucleation rate as a function of supercooling exhibits a maximum at a certain temperature, and decreases either for lower or higher supercooling. In fact, according to the classical nucleation theory, the higher the supercooling, the greater the driving energy for nucleation becomes, but the decrease of temperature gives rise to an increase of the viscosity disfavouring crystallization (Turnbull, 1969). That is, when for kinetic reasons crystallization does not occur at HTC, the probability that it happens at lower temperature is small and then it will take place at LTC through a crystallization process initiated in the other liquid phase. Once initiated, the crystallization process spreads over the two liquids.

Whatever the mechanism, a complete solidification of the melt is reached, occurring commonly at HTC or at LTC. The latter is the most probable event.

Evidence has been given for spinodal decomposition of viscous liquids into liquid phases by density fluctuation of small amplitude and large extent (Roberts et al., 1996; Klein et al., 1988; Olmsted et al., 1998).

Like was done for the original pindolol, the search for polymorphs generated by cooling the melt was undertaken by analysis of the fusion endotherms. Following an identical procedure, 60 fusion curves, resulting from samples cooled at $2{ }^{\circ} \mathrm{C} / \mathrm{min}$ and heated at $1{ }^{\circ} \mathrm{C} / \mathrm{min}$, were analysed. Most curves were fitted to two individual components, some to three and a few were single components. The clusters originated by the
$T_{\text {peak }}$ set were characterized by temperatures $170.0 \pm$ $0.2^{\circ} \mathrm{C}$ (III), $170.6 \pm 0.1^{\circ} \mathrm{C}$ (II) and $171.1 \pm 0.2^{\circ} \mathrm{C}$ (I). Frozen melt is once in a while a single polymorph (I, II or III), more often it is a mixture of polymorphs II and III, and a few times a mixture of polymorphs I and II, or I and III. The value found for the global fusion enthalpy was $58 \pm 2 \mathrm{~kJ} \mathrm{~mol}^{-1}$, which is not significantly different from that determined for the original substance. Attending to the values of $T_{\text {peak }}$, the original pindolol used in this investigation is a mixture of polymorphs I and III.

The two-phase separation of molten pindolol on cooling evidenced by DSC data for the crystallization could be observed by PLTM. Fig. 8 shows the main steps observed in some experiments on cooling molten pindolol at $2{ }^{\circ} \mathrm{C} / \mathrm{min}$. At $134.6^{\circ} \mathrm{C}$ in almost simultaneous processes the liquid separates out in two phases and the crystallization in one of them begins. The liquid phase separation is a very fast process and the frontiers of both liquid phases are clearly observed. The crystallization of $\mathrm{HTC}$ form ends at $133.0^{\circ} \mathrm{C}$, giving rise to a solid texture resembling paving parallelepipedic blocks ended by a triangular wedge microstructure. The nucleation-growth process in the other liquid phase occurs as the temperature reaches $74.5^{\circ} \mathrm{C}$, giving rise in the first step to a globular solid texture followed by a dendritic structure.

The crystallinity degree of the precipitated forms increases on heating as can be shown in the last two pictures of Fig. 8, which corresponds to the recent precipitated solids after heating at $5{ }^{\circ} \mathrm{C} / \mathrm{min}$. Aside some structural detailed transformation observed upon heating, an Ostwald ripening effect is well evidenced in the original dendritic structure.

A solid formed at around $100{ }^{\circ} \mathrm{C}$ followed by another one at $74{ }^{\circ} \mathrm{C}$ is another type of crystallization observed in a few experiments. The first solid formed exhibits a banding structure and the second one is identical to that described for that temperature (Fig. 9).

The most common behaviour exhibited by pindolol on cooling is the crystallization of the melt at a unique temperature value of about $75^{\circ} \mathrm{C}$. Fig. 10 shows a typical image for the crystallization at this temperature. The nucleation is initiated at $75^{\circ} \mathrm{C}$ and a mixture of forms is generated in a cellular crystalline front giving a heterogeneous structure.

Three polymorphic forms of pindolol with fusion temperatures within $1.1^{\circ} \mathrm{C}$ temperature range were 

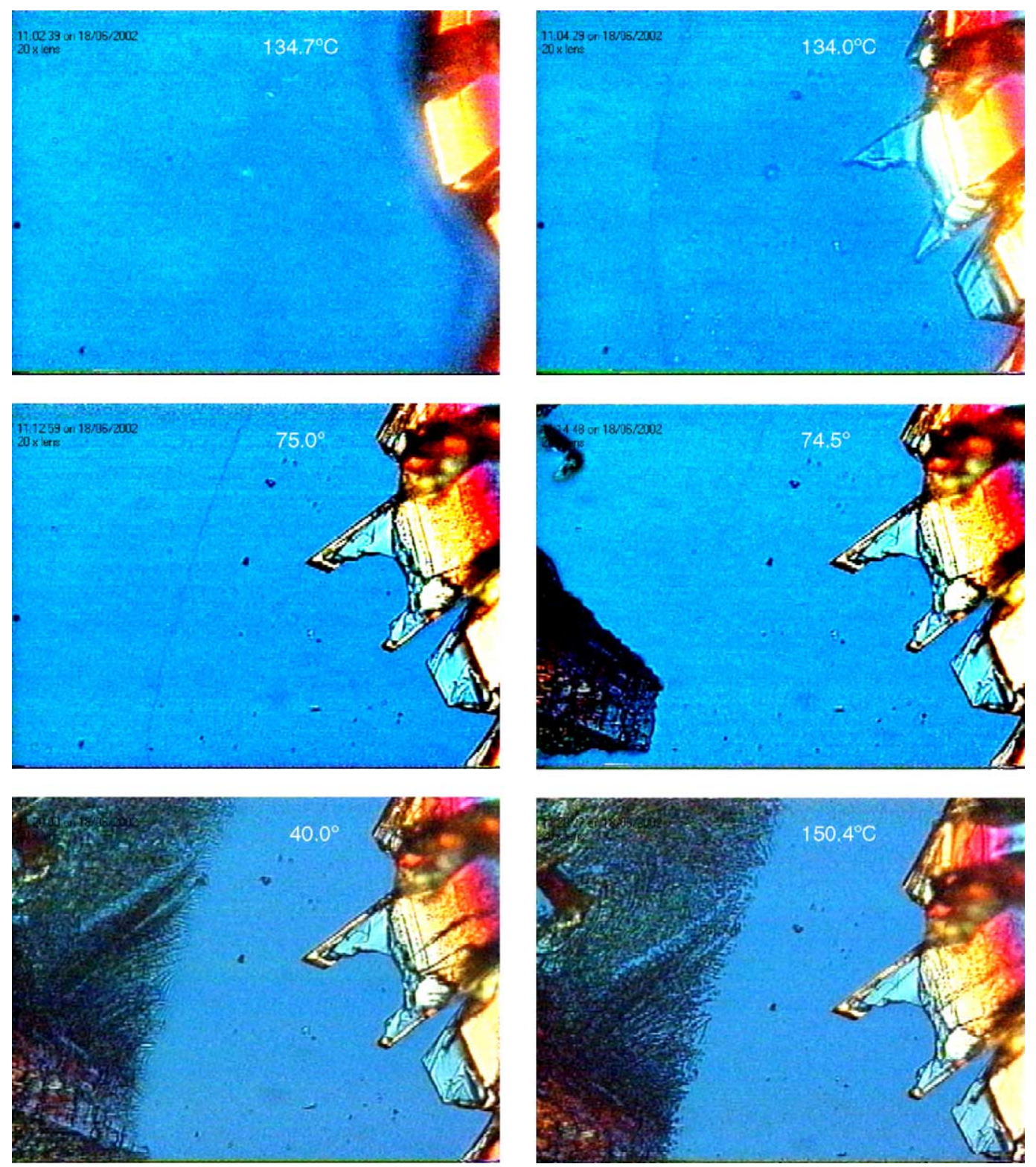

Fig. 8. Crystallization of molten pindolol: evidence of liquid separation and crystallization at HTC and LTC. Crystallinity increases on heating (cooling rate $=2{ }^{\circ} \mathrm{C} / \mathrm{min}$, heating rate $=5^{\circ} \mathrm{C} / \mathrm{min}$ ).

identified upon freezing the melt. The small differences found for the fusion temperatures indicate close values for solid lattice energies. This is an expected result for a compound having a flexible molecule as that of pindolol. By molecular mechanics, 20 different backbone chain conformations for the pindolol molecule in an energy range of $8.1 \mathrm{~kJ} \mathrm{~mol}^{-1}$ above the lowest energy conformation are observed (unpublished data by the authors). Although the number of molecular conformations will be drastically reduced in liquid and solid states, different conformations involving small energy differences are expected. 

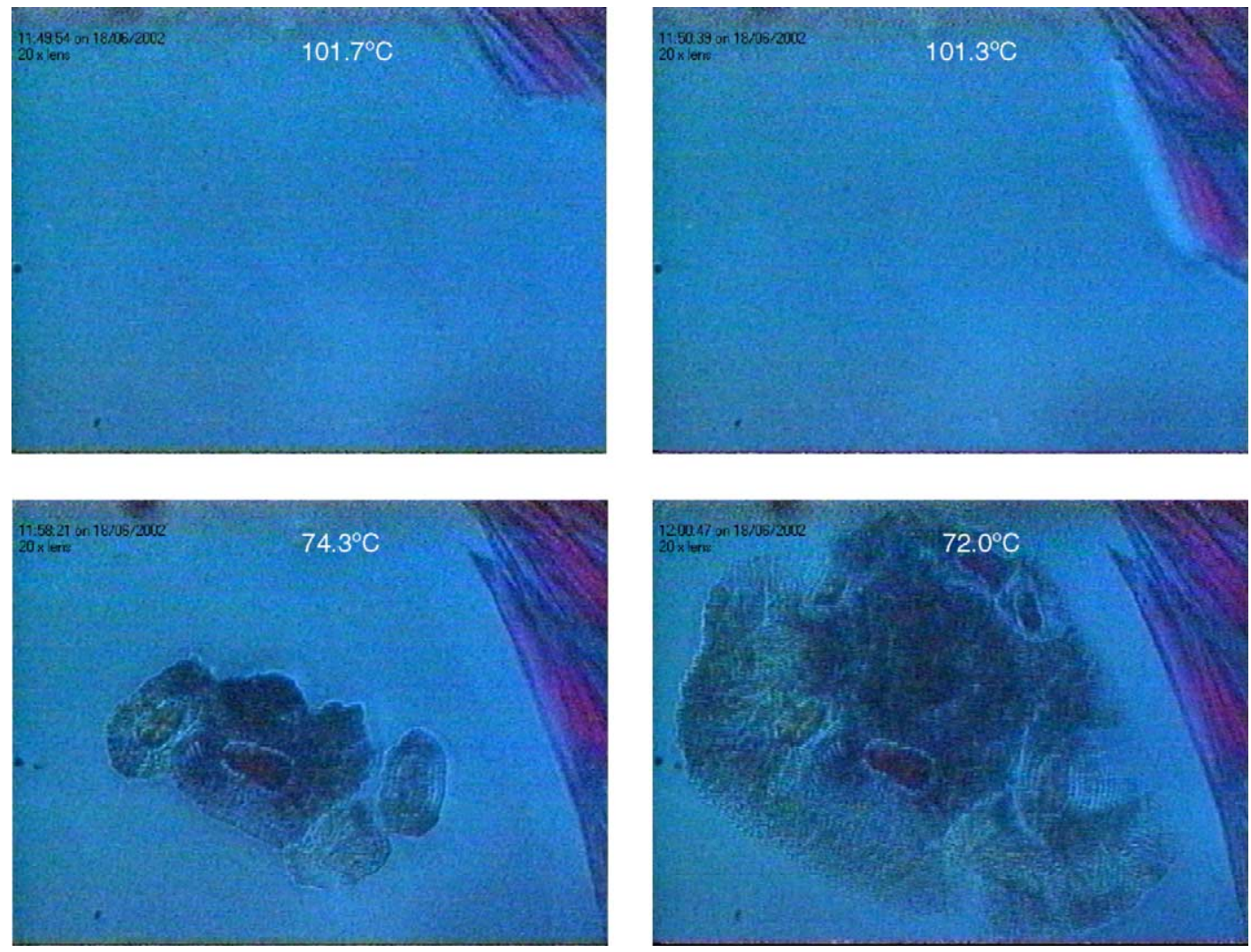

Fig. 9. Crystallization of molten pindolol: solidification at an atypical temperature and LTC (cooling rate $\left.=2{ }^{\circ} \mathrm{C} / \mathrm{min}\right)$.

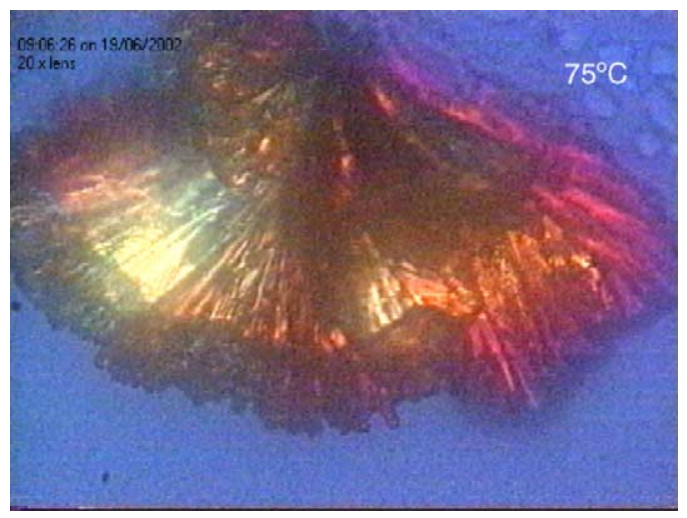

Fig. 10. Crystallization at LTC giving rise to a mixture of forms (cooling rate $=2{ }^{\circ} \mathrm{C} / \mathrm{min}$ ).
Attending to structural similarity among the polymorphic forms, the great probability for their simultaneous crystallization is understandable.

We are aware of two research works performed on the structure of pindolol using X-ray diffraction. The samples studied in one of these works were obtained by slow evaporation of a methanol solution (Gradet et al., 1976), and the samples for the other were prepared by crystallization from ethanol (Chattopadhyay et al., 1995).

By comparing the data given in both papers, we came to the conclusion that the samples correspond to different structures. The crystallographic system and space group proposed in both publications are identical; the figures obtained for bond lengths and angles are in agreement, but there are differences for the angles defined by the atoms of the isopropilamino moiety. Also, different values are assigned to the $\mathrm{C}(11) \mathrm{N}(12) \mathrm{H}(12)$ and $\mathrm{C}(13) \mathrm{N}(12) \mathrm{H}(12)$ torsion angles. 


\section{Conclusions}

Some points discussed in this work deserve to be referred to as concluding remarks. DSC is a valuable research tool to characterize polymorphic forms even separated by small energy differences. It is a very sensitive technique to structural variations, and for many solids, the DSC fusion curves are obtained in the highest crystallinity degree of the material. However, to derive advantage of the method, attention has to be paid to the experimental procedures and a detailed statistical analysis of the results is required. In fact, to obtain reliable fusion curve patterns for the system under study, it is necessary to avoid contact of molten pindolol with oxygen. The overlapped fusion curves of the polymorphic forms were separated by peak fitting analysis, and the values determined for the $T_{\text {peak }}$ grouped into clusters, each one corresponding to a distinct polymorph. Three polymorphs were identified by crystallization of molten pindolol and only two of these were present in the pindolol studied before being melted.

Interesting features are exhibited by the crystallization process from the melt. Solidification is initiated by nucleation at three distinct temperatures. That occurring at higher temperatures is sometimes by-passed and than the solidification takes place at the lower temperature. In DSC experiments, usually only one exotherm is observed localized at the higher temperature or at the lower one. This behaviour was interpreted admitting the decomposition of the melt in two liquid phases, each one requiring a different supercooling for nucleation.

\section{References}

Bernstein, J., 1987. Conformational polymorphism. In: Desiraju, G.R. (Ed.), Organic Solid State Chemistry. Elsevier, Amsterdam (Chapter 13).
Bernstein, J., Davey, R.J., Henck, J.O., 1999. Concomitant polymorphs. Angew. Chem. Int. Ed. 38, 3440-3461.

Bratchell, N., 1989. Chemometrics and Intelligent Laboratory Systems. Elsevier, Amsterdam (Chapter 7).

Brittain, H.G., Byrn, S.R., 1999. Structural aspects of polymorphism. In: Brittain, H.G. (Ed.), Polymorphism of Pharmaceutical Solids. Marcell Dekker, New York (Chapter 3).

Chattopadhyay, T.K., Palmer, R.A., Mahadevan, D., 1995. Molecular and absolute crystal structure of pindolol-1- $(1 \mathrm{H}$-indol4-yloxy)-3-[(1-methylethyl)amino]-2-propanol: a specific betaadrenoreceptor antagonist with partial agonist activity. J. Chem. Crystallogr. 25, 195-199.

Gradet, P.M., Goursolle, M., Leger, J.M., Colleter, J.C., 1976. Structure Cristalline du Pindolol, (hydroxy-2 isopropylamino-3 propoxy)-4 indole. Acta Cryst. B32, 17-20.

Klein, H., Schmitz, G., Woermann, D., 1988. Evidence for spinodal decomposition in a single component fluid. Ber. Busenges. Phys. Chem. 92, 870-872.

Mahrous, M.S., Issa, A.S., Ahmed, N.S., 1992. Oxidants for the colorimetric determination of pindolol. Talanta 39, 69-72.

Mullin, J.W., 1993. Crystallization. Butterworth Heinemann, Oxford (Chapter 5).

Olmsted, P.D., Poon, W.C.K., McLeish, T.C.B., Terrill, N.J., Ryan, A.J., 1998. Spinodal-assisted crystallization in polymer melts. Phys. Rev. Lett. 81, 373-376.

Origin, 2002. Scientific Graphing and Analysis Software, Version 7. OriginLab Corporation, Northampton.

Oxtoby, D.W., Talanquer, V., 1996. Nucleation on a solid substrate: a density functional approach. J. Chem. Phys. 104 (4), 1483-1492.

Remers, W.A., 1972. In: Houlihand, W. (Ed.), Heterocyclic Compounds, Indoles, part I. Wiley-Interscience, New York.

Roberts, C.J., Panagiotopoulos, A.Z., Debenedetti, P.G., 1996. Liquid-liquid immiscibility in pure fluids: polyamorphism in simulations of a network forming fluid. Phys. Rev. Lett. 77, 4386-4389.

Sabbah, R., Wu, A.X., Chickos, J.S., Leitão, M.L.P., Roux, M.V., Torres, L.A., 1995. Reference materials for calorimetry and differential thermal analysis. Thermochim. Acta 331, 93-204.

Stenlake, J.B., 1979. Foundations of Molecular Pharmacology, vol. 1. The Athlone Press of University of London, London.

Turnbull, D., Bagley, B.G., 1975. In: Hannay, N.B. (Ed.), Treatise on Solid State Chemistry (Changes of State), vol. 5. Plenum Press, New York (Chapter 10).

Turnbull, D., 1969. Under what conditions can a glass be formed. Contemp. Phys. 10, 473-488. 